\title{
Using Systemizing-Empathizing Theory to Explore Individual Differences in Resilience by Brain Types
}

\author{
$\mathrm{Nao} \mathrm{Yu}$ \\ College of Science, Jiangsu University of Science \& Technology, Zhenjiang, Jiangsu 212003, China \\ Email:1257024455@qq.com
}

\begin{abstract}
As a key competence to bounce back from adversity, resilience is crucial for maintaining positive physical and mental health. However, not everyone is able to overcome stressful situations and individuals demonstrate various levels of resilience. In the present study, 120 undergraduates from China completed questionnaires on their resilience, systemizing and empathizing tendency. No gender difference was revealed in resilience. However, individuals with extreme brain types (high empathizers and high systemizers) demonstrated stronger resilience than those with more balanced brain types. Nonetheless, gender typical brain type group (empathizing-oriented women and systemizing-oriented men) showed similar level of resilience with the gender atypical brain type group (systemizing-oriented women and empathizing-oriented men). Both systemizing and empathizing were positively correlated with resilience. Such results indicated that excellence in interpersonal or analytical skills may facilitate strategies to deal with adversity.
\end{abstract}

Keywords: resilience, individual differences, empathizing and systemizing

\section{INTRODUCTION}

\subsection{Resilience}

With the rapid development of economy and technology, great changes have taken place in people's life both in physical and mental aspects. College students, who are in the transitional period in their life, are going to leave the ivory tower and enter the real world. Many of them are equipped with the theoretical knowledge from the class but lack practical experience of how to effectively cope with stressful life events and conquer various challenges. Increasing numbers of Chinese university students were found to suffer from mental issues, such as anxiety [1], depression [1-3], somatization [4], and even suicides [5]. These mental issues have brought about tremendously detrimental effects on their permanent development.

Under such circumstances, mental health education plays an essential and indispensable role in modern education system in the long run. In order to lay the substantial foundation for empowering college students to further contribute to the society, it is considered urgent for psychologists and educators to make a joint effort to strengthen the ability of young adults to bounce back from adversity, which is termed as resilience in literature [6].

According to prior research, resilient individuals have shown various positive behaviors that benefit all aspects of their life. Zimmerman et al., (2013) [7] found resilient students were more likely to have high self-esteem, strong family relationships, a high degree of parental monitoring, and immense social supports. In addition, high-resilient college students were also found to adapt to school better, showing lower levels of suicidal ideation [8], higher study motivation [9], and better interpersonal skills [10] as compared with lower-resilient students. Furthermore, Zhang (2014) [11] found a negative relationship between resilience and crisis personality, meaning that high-resilient individuals were less likely to suffer from psychological crisis. As suggested by Tugade \& Fredrickson (2004) [12], these positive results may be attributed to the situation that high-resilient individuals intended to feel more positive emotions (e.g. eagerness, excitement, happiness, and interest) than low-resilient individuals when facing life events and challenging situations. In summary, resilience is exceptionally essential and beneficial for college students' far-reaching mental health and well-being.

\subsubsection{Gender difference in resilience}

What intrigued many psychologists most is the finding that, as a personality trait, resilience may differ between women and men [13]. Dumont \& Provost (1999) [14] indicated that appropriate coping strategies (a constellation of strategies which healthy people develop as problem solvers) are beneficial for adolescents to resist stress and depression. However, men and women would apply distinct coping strategies to deal with stressful life events. A study conducted by De la Fuente et al., (2013) [15] revealed that female university students performed better on emotion-oriented and problem-centered coping strategy and were more inclined to resort to social supports, whereas men were more inclined to resort to instrumentality (e.g. finance and romance) and 
independence [16]. Though men and women apply distinctive coping strategies for daily challenges, existing evidence showed no significant differences in resilience between men and women $[11,15,17]$. In the present study, I argue that the lack of evidence for gender difference in resilience in literature may due to the fact that most of the studies referred to biological sex rather than gender brain types as the indicator to differentiate between women and men. To mend this gap, the present study aimed to explore whether the gender brain type could serve as a better indicator for individual difference in resilience.

\subsection{Gender brain types: Empathizing-Systemizing (E-S) Theory}

According to the E-S theory, individuals could have two gender brain types: empathizing and systemizing [18, 19]. Empathizing is defined as the drive to identify the mental states of others in order to predict their behavior and respond with an appropriate emotion [20]. Systemizing is defined as the drive to analyze a system in terms of the rules that govern it to predict its behavior [20]. In addition, Baron-Cohen (2002) [18] has indicated the female brain type and male brain type separately corresponded to empathizing superiority and systemizing superiority in individuals. The female brain type referred to those whose empathizing was more dominating than systemizing. The male brain type referred to those whose systemizing was more dominating than empathizing [21, 22]. Furthermore, prior research demonstrated that there were typical and atypical individuals in gender brain types. The typical individuals referred to those whose brain sex is consistent with their biological sex, the atypical individuals referred to those whose brain sex is opposite of their biological sex. It demonstrated that women could have 'male brain' $(\mathrm{S}>\mathrm{E})$ and men could also have 'female brain' $(E>S)$ [23].

Previous studies have demonstrated that gender brain types of empathizing-systemizing may be a more influential predictor in gender difference than biological sex in some fields (e.g. occupations, interests, hobbies, social skills, gender identity, and degree subject) [23, 24]. As such, I hypothesized that, regardless of the biological sex, it is the gender brain type that may influence individual's ability to cope with and bounce back from adversities.

Moreover, evidence showed that empathizing and systemizing traits were independent in women, but largely dependent in men [25]. The association between empathizing and systemizing in men and women may determine the distinct degrees of empathizing and systemizing to some extent. Because the gender brain types of empathizing-systemizing may correlate with individual coping strategy when facing daily events, it would determine individual resilient capacity [23]. Thus, the relationship between gender brain types and resilience remained to be further investigated.

\subsection{Correlation among gender, Empathizing-systemizing and resilience}

Prior studies indicated that the empathizing-oriented individuals have preference on understanding and interacting with people, whereas systemizing-oriented individuals have preference on analyzing rule-based systems [23]. Sociocontextual factors (e.g. supportive relations, community resources) are found positively related with resilience [26]. In this case, empathizing-oriented individuals who prefer to socialize with people might receive more social support than systemizing-oriented individuals and such situation is very likely to promote their resilience [27]. Regardless of biological sex, female brain type individuals who are deemed of empathizing-oriented brain might be more resilient than their male brain-typed counterparts with systemizing-oriented brain. Given that not all men are of male brain type [23], the female brain type men might be more resilient than the male brain type men. In this case, it is reasonable to draw a hypothesis that empathizing-oriented individuals might be more resilient than systemizing-oriented individuals.

\subsection{Gender typical and atypical brain type groups differences in resilience}

Building upon and furthering E-S theory [28], individuals were categorized as two groups by Svedholm-Häkkinen et al., (2018) [23]: gender typical brain type group (empathizing-oriented women, systemizing-oriented men) and gender atypical brain type group (empathizing-oriented men, systemizing-oriented women). The "typical" refers to those whose brain types are consistent with their biological sexes, the "atypical" refers to those whose brain types go contrary to their biological sexes. Additionally, Svedholm-Häkkinen and his colleagues (2018) [23] also indicated that, in a range of social cognitive and personality traits (e.g. social connectedness, hobbies, occupations, skills), the gender typical brain type were in line with the same-sex peers, whereas gender atypical groups were in line with the opposite sex.

Therefore, one possible situation may be that the sex role identity of the gender atypical group remains inconsistent with social expectations. Sex role identity has been classically defined as an acquired self-concept of an individual's degree of masculinity or femininity [23]. Therefore, individuals may have the strong tendency to keep away from same-sex individuals who have inconsistent sex role identity with social expectations. Moreover, the gender atypical groups were different from gender typical groups in hobbies, occupations and behavioral norms, it possibly made the gender atypical group easily suffer from the gender typical group's neglect, isolation, and even disrespect due to social expectations, and therefore become less resilient than the gender typical group. 
From another perspective, the gender atypical group who did not conform to gender role stereotypes may become distinctive, popular and sociable with the opposite sex peers owing to their traits more in line with the opposite sex peers of typical cognitive profiles, and therefore become more resilient than the gender typical group. According to above two distinct situations, it was reasonable to hypothesize that there may be a significant difference in resilience which closely related with social interaction between gender typical and atypical brain type groups.

In the present study, I explored the association among resilience, women and men, empathizing and systemizing, gender typical and atypical brain type groups, and formed four questions as followed:

1) Is there significant difference in resilience between men and women?

2) Is there significant difference in resilience by gender brain types of empathizing and systemizing?

3) What is the relationship between resilience, empathizing and systemizing?

4) Is there significant difference in resilience between gender typical and atypical brain type groups?

\section{METHODOLOGY AND METHOD}

\subsection{Participants and procedures}

Participants consisted of 120 university students, 61 of them were men and 59 were women. Regarding their major subjects, 55 major in science and 65 in social science. Their age ranges from 19 to 23. Only participants who replied to all items were included in the final analysis. Students who studied law, business administration, tourism management, accounting, administration specialty, philosophy and political sciences, political science and public administration, public management, were categorized as social science students; while those who studied applied statistics, information and computing science were categorized as science students.

All participants were informed of the aim of study and were recruited through their departments from two universities located in Jiangsu and Chongqing. All questionnaires were directly handed out to all recruited participants once in the classroom and were completed together under the administration of the researcher. The sequences of the three questionnaires were counterbalanced to avoid order effect.

\subsection{Measurements}

\subsubsection{Empathizing: Empathy Quotient (EQ)}

Empathizing was assessed using the 40-item version of the Empathy Quotient-Short (EQ) scale [29]. The Empathizing
Quotient-Short was administrated to measure the participants' drive to identify the mental states of others in order to predict their behavior and respond with an appropriate emotion. It's a self-report questionnaire containing 40 items using examples from everyday life in which empathizing can be used to varing degrees. For instance, "I really enjoy caring for other people", "it is hard for me to see why some things upset people so much." Within the questionnaire, approximately half the items were reversely scored to avoid a response bias. Each had a forced-choice format on a 4-point response scale, including strongly disagree, slightly disagree, agree, strongly agree and was converted into scores of $0,0,1$, and 2 according to the concrete questions. The sums of these scores were then calculated. The scale with missing data is excluded.

\subsubsection{Systemizing: Systemizing Quotient ( $S Q)$}

Systemizing was assessed using the 75-item version of the Systemizing Quotient (SQ) scale [29]. The Systemizing Quotient was administrated to measure the participants' drive to analyze and control a system in terms of the rules that govern it to predict its behavior. It's a self-report questionnaire containing 75 items using examples from everyday life in which systemizing can be used to varing degrees. For instance, "I find it difficult to learn how to programme video recorders", "I like music or book shops because they are clearly organized". Within the questionnaire, approximately half the items were reversely scored to avoid a response bias. Each had a forced-choice format on a 4-point response scale, including strongly disagree, slightly disagree, agree, strongly agree and was converted into scores of $0,0,1$, and 2 according to the concrete questions. The sums of these scores were then calculated. The scale which has missing data is excluded.

\subsubsection{Resilience: Conner-Davidson Resilience Scale (CD-RISC)}

The resilience was assessed using the Chinese version of the CD-RISC. This scale comprises of 25 items. Participants were asked to finish the scale with reference to their experience of previous month. For instance, "I can see the humorous side of things", "I would try my best whatever the result is." Each had a forced-choice format on a five-point response scale, including "never, hardly, sometimes, usually, and always" and was converted into scores of $0,1,2,3$ and 4 according to the concrete questions. The total score ranges from 0 to 100 , with higher scores indicating higher levels of resilience. It assesses five factors: (1) personal competence, high standards and tenacity, (2) tolerance of negative affect and strengthening effects of stress, (3) positive acceptance of change, and secure relationships, (4) control and (5) spiritual influences [15]. Researchers have consistently reported good reliability and validity of this scale [30, 31]. 


\section{RESULTS}

\subsection{Descriptive statistic}

First of all, descriptive data of the involved variables are presented so the readers can gain general knowledge of the status of the current sample on each variable. Table 1 illustrates the mean (M), standard deviation (SD) and the range of current participants' EQ, SQ and CD-RISC scores.

Table 1 Descriptive data

\begin{tabular}{ccccc}
\hline \multirow{2}{*}{ Variable } & \multirow{2}{*}{ M } & SD & \multicolumn{2}{c}{ Range } \\
& & & Potential & Actual \\
\hline EQ & 36.62 & 12.39 & $0-80$ & $11-66$ \\
SQ & 54.72 & 17.70 & $0-150$ & $26-117$ \\
CD-RISC & 64.41 & 12.90 & $0-100$ & $33-100$ \\
\hline
\end{tabular}

\subsection{Gender differences (Independent sample's T test)}

\subsubsection{Women versus men's EQ scores}

In terms of the gender disparity on the EQ scores, averaged across the entire sample, women $(\mathrm{M}=39.85$, SD $=12.244)$ scored higher than men $(\mathrm{M}=33.49, \mathrm{SD}=$ 11.799). This difference, 6.36 (women's minus men's), BCa 95 CI [-10.702, -2.009], was significant $\mathrm{t}(118)=$ $-2.896, p=0.005$, two-tailed; such results indicated that women in general showed higher empathizing tendency than men. Figure 1 illustrated the means of EQ scores of women and men.

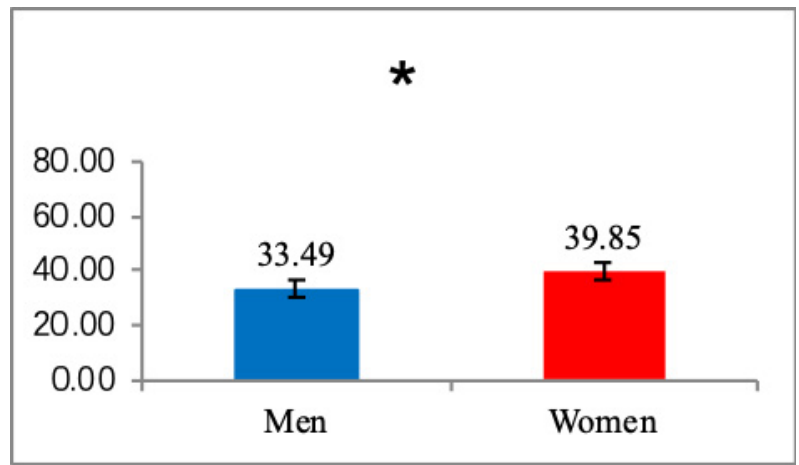

Figure 1 Comparison of means of women and men's EQ scores

Significant difference is marked by asterisk (*)

\subsubsection{Women versus men's $S Q$ scores}

In terms of the gender disparity on the SQ scores, averaged across the entire sample, women $(\mathrm{M}=56.14, \mathrm{SD}=19.580)$ scored higher than men $(\mathrm{M}=53.34, \mathrm{SD}=15.708)$. This difference, 2.79 (women's minus men's), BCa 95 CI $[-9.198,3.615]$, was not significant $\mathrm{t}(118)=-0.863$, $\mathrm{p}=0.390$, two-tailed; such results indicated that there was no significant difference in systemizing tendency between women and men. Figure 2 illustrates the means of SQ scores of women and men

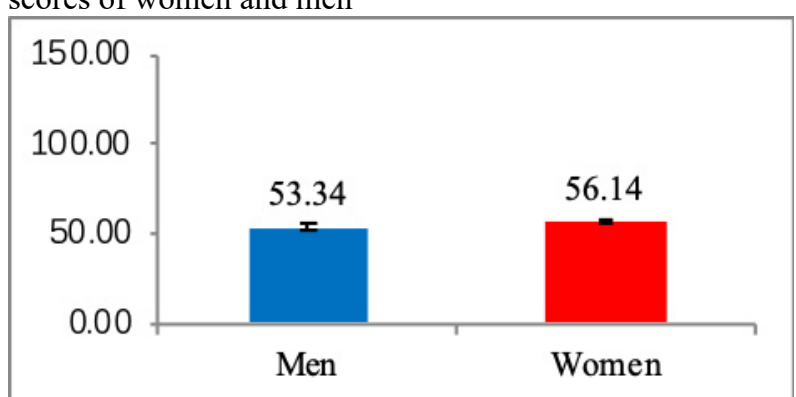

Figure 2 Comparison of means of women and men's SQ scores

\subsubsection{Women versus men's CD-RISC scores}

In terms of the gender disparity on the CD-RISC scores, averaged across the entire sample, women $(\mathrm{M}=66.59$, SD $=13.765)$ scored higher than men $(\mathrm{M}=62.30$, $\mathrm{SD}=$ 11.711). This difference, 4.30 (women's minus men's), BCa 95 CI [-8.913, 0.317], was not significant $t(118)$ $=-1.844, \mathrm{p}=0.068$, two-tailed; such results indicated that there was no significant gender difference in resilience. Figure 3 illustrated the means of CD-RISC scores of women and men.

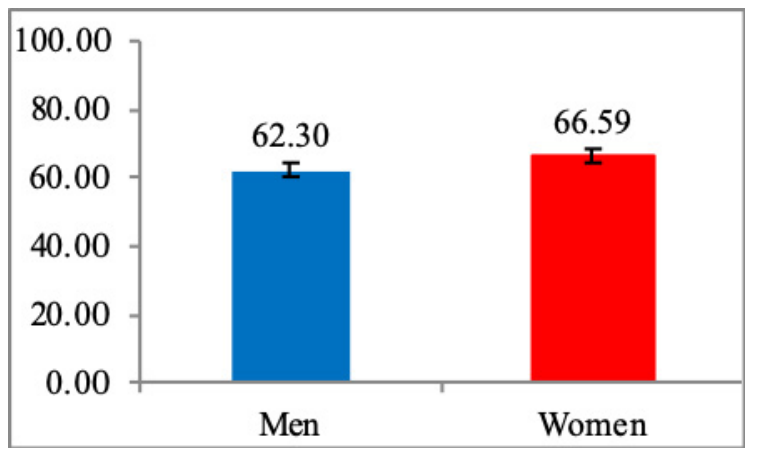

Figure 3 Comparison of means of women and men's CD-RISC scores

\subsection{Correlations among variables (Pearson product-moment correlations)}

In order to examine the relationships among empathizing, systemizing and resilience, the results are illustrated in Table 2. The following correlations are worth paying attention to. 


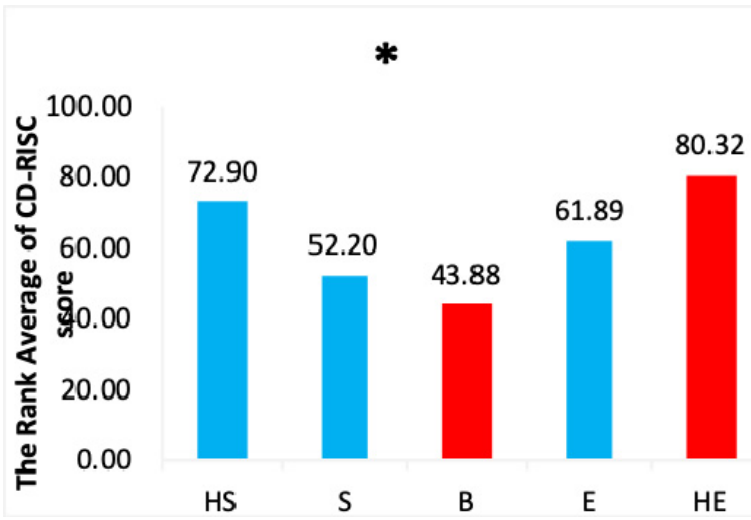

Table 2 Correlations between variables of the study

\begin{tabular}{|c|c|c|c|}
\hline & 1 & 2 & 3 \\
\hline $1 . \mathrm{EQ}$ & 1 & $0.435^{* *}$ & $0.535^{* *}$ \\
\hline $2 . \mathrm{SQ}$ & & 1 & $0.470^{* *}$ \\
\hline 3.CD-RISC & & & 1 \\
\hline
\end{tabular}

**. At the 0.01 level (two-tailed), the correlation is significant. Pearson product-moment correlations are presented above the diagonal

Table 2 suggested that the EQ, SQ, and CD-RISC are significantly and positively correlated with each other. The Pearson's correlation between EQ and SQ: $r(120)=0.435$, $\mathrm{p}<0.01$, EQ and CD-RISC: $\mathrm{r}(120)=0.535, \mathrm{p}<0.01$, SQ and CD-RISC: $\mathrm{r}(120)=0.470, \mathrm{p}<0.01$, statistically correlated. Correlation analysis results demonstrated that both of empathizing and systemizing tendency are significantly positively related with resilience.

\subsection{Individual differences in resilience by brain types}

In this paper, I intend to classify individuals as five brain types based on their SQ and EQ performance. Following Svedholm-Häkkinen et al., (2018) [23], I transformed the raw EQ and SQ scores from each participant into the same scale. Then I subtracted the standard EQ score from the standard SQ score for each participant. I called this difference ' $\mathrm{D}$ ' score. A high $\mathrm{D}$ score just can be attained by a high SQ score with a low EQ score. A low D score reflects the difference between scores in the EQ and SQ is small. The greater the D score in a positive direction, the stronger is one's systemizing, and the greater the D score in a negative direction, the stronger one's empathizing [20]. Descriptive statistic results showed the mean was 0.05, standard deviation was 10.61. A D score falling below from -2.07 to 2.17 (within $\mathrm{M} \pm 0.2 \mathrm{SD}$ ) is termed type Balanced (B), from 2.17 to below $10.66(\mathrm{M}+0.2 \mathrm{SD}<\mathrm{D}<$ $\mathrm{M}+\mathrm{SD}$ ) is termed type Systemizing (S), 10.66 and over (D $>\mathrm{M}+\mathrm{SD}$ ) is termed type High Systemizing (HS). A D score falling from -10.56 to above -2.07 (M-SD> $\mathrm{D}>\mathrm{M}-0.2 \mathrm{SD}$ ) is termed type Empathizing (E), and -10.56 and below ( $<\mathrm{M}-\mathrm{SD}$ ) is termed type High Empathizing (HE). The relevant information of brain type classification are shown in Table 3. The rank average of CD-RISC for each brain type is shown in figure 4 .
Figure 4 The rank average of CD-RISC for each brain type. Significant difference is marked by asterisk (*)

As the Kruskal-Wallis test results indicted, the effect size of balanced and high-empathizing were 0.413 . There was a significant difference in resilience by gender brain types. The pairwise comparison results indicated that there was a significant difference in resilience between groups of high-empathizing and balanced $(\mathrm{p}=0.022)$, but no significant difference of resilience between other brain type groups. Additionally, I further done the descriptive statistic of separate raw EQ and SQ scores of the high-empathizing and balanced brain types. According to the descriptive statistic results, SQ and EQ scores of type high empathizing (HE) are higher than those of type balanced (B) on average, especially the EQ score. Furthermore, the High Empathizing group of "D scores" was classified as High-Low group of EQ and SQ scores; the Balanced group of "D scores" was classified as Low-Low group of EQ and SQ scores. 


\subsection{Gender typical versus atypical brain type groups' CD-RISC scores}

Table 3 Classifications of brain type based upon median positions

\begin{tabular}{|c|c|c|c|c|c|}
\hline Brain Type & $\begin{array}{c}\text { High } \\
\text { systemizing }\end{array}$ & Systemizing & Balanced & Empathizing & $\begin{array}{c}\text { High } \\
\text { empathizing }\end{array}$ \\
\hline Brain Sex & Extreme male & Male & Balanced & Female & Extreme female \\
\hline $\begin{array}{c}\text { Defining } \\
\text { characteristic }\end{array}$ & $\mathrm{S}>>\mathrm{E}$ & $\mathrm{S}>\mathrm{E}$ & $\mathrm{S} \approx \mathrm{E}$ & $\mathrm{S}<\mathrm{E}$ & $\mathrm{S}<<\mathrm{E}$ \\
\hline $\begin{array}{l}\text { Brain Boundary } \\
\text { (median }=0.05, \\
\text { standard } \\
\text { deviation }=10.61 \\
\text { ), cut-off points } \\
\text { were } \mathrm{M} \pm 0.2 \mathrm{SD} \\
\text { and } \mathrm{M} \pm \mathrm{SD} \text {, } \\
\text { respectively. }\end{array}$ & $\mathrm{D}>10.66$ & $2.17<\mathrm{D}<10.66$ & $-2.07<\mathrm{D}<2.17$ & $-10.56<\mathrm{D}<-2.07$ & $D<-10.56$ \\
\hline $\begin{array}{c}\text { Percentile } \\
\text { (per) }\end{array}$ & Per $>85.9$ & $55.9<$ Per $<85.9$ & $41.7<$ Per $<55.9$ & $12.5<$ Per $<41.7$ & Per $<12.5$ \\
\hline Male \% & 10 & 43 & 16 & 26 & 5 \\
\hline Female $\%$ & 15 & 15 & 12 & 34 & 24 \\
\hline $\begin{array}{l}\text { lowing the instruct } \\
\text { 18) [23] as well } \\
\text { sideration, cut-off } \\
\text { up that "D score" } \\
\text { ned as type syste } \\
-0.6 \mathrm{SD} \text { ) is termed } \\
\text { up comprised of } 27 \\
\text { systemizing-oriente } \\
\text { mpathizing-orientec } \\
\text { men. In terms of th }\end{array}$ & $\begin{array}{l}\text { ns of Svedholm } \\
\text { taking limited } \\
\text { int was located } \\
\text { alling above } 6.4 \\
\text { izing, and fall } \\
\text { type empathiz } \\
\text { empathizing-orie } \\
\text { men. Atypical gr } \\
\text { men and } 12 \text { sys }\end{array}$ & $\begin{array}{l}\text { kkinen et al., } \\
\text { ple size into } \\
\pm 0.6 \mathrm{SD} \text {. The } \\
\mathrm{M}+0.6 \mathrm{SD}) \text { is } \\
\text { below }-6.32 \\
\text { The typical } \\
\text { women and } \\
\text { comprised of } \\
\text { izing-oriented } \\
\text { atypical brain }\end{array}$ & $\left.\begin{array}{c}100.00 \\
80.00 \\
60.00 \\
40.00 \\
20.00 \\
0.00\end{array}\right]$ & Typical & Atypical \\
\hline
\end{tabular}

across the entire sample, typical group $(\mathrm{N}=40, \mathrm{M}=66.95$, $\mathrm{SD}=12.17)$ scored higher than atypical group $(\mathrm{N}=19$, $\mathrm{M}=68.68, \mathrm{SD}=15.42$ ). This difference, -1.73 (typical's minus atypical's), BCa 95 CI $[-9.14,5.68]$ was not significant $\mathrm{t}(57)=-0.47, \mathrm{p}=0.64$, two-tailed; such results indicated that there was no significant difference in resilience between gender typical and atypical brain type groups. Figure 5 illustrated the means of CD-RISC scores' means of typical and atypical groups.
Figure 5 Comparison of CD-RISC scores' means of typical and atypical groups

\section{DISCUSSION}

Prior research has investigated the association among resilience, biological sex, and other numerous variables, such as social connectedness [14], coping strategy [15], personality [32], occupation [28]. The present study is the first-to-date to explore the association among resilience, systemizing and empathizing. 


\subsection{Gender differences in empathizing, systemizing and resilience}

Consistent with previous findings [20], female displayed higher empathizing than males. One possible explanation may be that, compared with men, female superiority in empathizing may result from women's social desirability and sex role identity, which enabled them to be more inclined to keep consistency with social expectations, and further caused strong tendency in women to report higher empathizing [23]. Another possible explanation could be that women are indeed more empathizing than men owing to their stronger tendency for interacting with people [15]. However, in contrast to prior research $[22,28]$, women from the present study displayed higher systemizing than their male counterparts. Such results may due to the fact that nearly half of the female participants are undergraduates majoring in statistics who received intensive mathematical trainings. Evidence has demonstrated that students who study mathematical-intensive scientific subjects are more systemizing-driven, whereas humanities students are more empathizing-driven [33]. Even female participants who were classified as social science students received mathematical training owing to their course requirement, such as accounting, business administration. Nevertheless, due to my observations, male participants occasionally buried themselves in computer games and relationship, therefore could not focus on their academic development. In this case, systemizing abilities in male participants were not trained as well as female participants in the present study. The lack of trainings to mathematics-related courses for male participants in the present study may lead to the gender gap in systemizing.

Consistent with prior research [11, 15, 17], gender difference in resilience was not significant in this study. As Morano (2010) [17] argued, resilience is a complex and multivariable process, the protective and risk factors for resilience correlated with each other according to concrete situations. From the developmental perspective, it may be more meaningful to take resilience as a dynamic and persistently changing process instead of purely treating it as an internally and innately personal attribute.

\subsection{Relationships among empathizing, systemizing and resilience}

Evidence in the present study indicated that both systemizing and empathizing were positively correlated with resilience. Svedholm-Häkkinen \& Lindeman (2016) [28] found that the "balanced group" of High-High group enjoyed the strengths of both of empathizing and systemizing relevant dimensions (e.g. friendship relations, social intelligence, grades, and sex role identity), but the Low-Low group, who were equally classified as the "balanced group", were nearly inferior to all dimensions compared with the High-High group. As a consequence, the High-High group superiority and Low-Low group inferiority in empathizing and systemizing relevant dimensions which closely correlated with resilience may be explained by the correlation results of present study.

Furthermore, it could be expected that individuals of high empathizing tendency receive more social support and consequently possess better ability to bounce back from adversities [23]. According to Goldenfeld et al., (2007) [22], extremely low empathizing and high systemizing are related with the dimensions of autistic traits, which may exert potentially great influence on individual resilience. Thus, it might draw the conclusion that even though the extreme systemizing tendency is associated with autistic traits [22], proper systemizing capacity is of help to promote resilience.

\subsection{Individual differences in resilience by gender brain types}

The Kruskal-Wallis test results indicated that there was a significant difference in resilience by gender brain types: the High-Empathizing group ranked highest, High-Systemizing group ranked second, Empathizing group ranked third, Systemizing group ranked forth, Balanced group ranked lowest. It is worth paying more attention that balanced group of equal empathizing and systemizing tendency, whom was expected to adapt themselves comfortably to daily events, scored lowest in resilience. According to Svedholm-Häkkinen \& Lindeman (2016) [28], the balanced brain type comprised of High-High group who were strong on both of empathizing and systemizing and Low-Low group who were weak on both of empathizing and systemizing. Thus, it was necessary to differentiate the low-low and high-high brain types in the balanced group in future studies.

According to the descriptive statistic of raw scores of EQ and SQ, I classified those whose score were above the mean as High-High group, and whose score is below the mean as Low-Low group. Table 4 suggests that High-Empathizing group based on "D" score are strong on empathizing ( $88 \%$ above the Mean) and weak on systemizing ( $24 \%$ above the Mean) on average, and belonged to High-Low group. Balanced group based on "D" score are weak on both of empathizing (24\% above the Mean) and systemizing (29\% above the Mean), and therefore belonged to Low-Low group.

For the purpose of exploring the hidden rules in a more scientifically rigorous fashion, I also implemented statistical analysis to explore the rest three of High-Systemizing, Systemizing, and Empathizing groups of their raw EQ and SQ scores. As shown in Table 4, High-Systemizing group based on " $\mathrm{D}$ " score are weak on empathizing $(27 \%$ above the Mean) and strong on systemizing ( $87 \%$ above the Mean), and belonged to the Low-High group. Empathizing group based on "D" score are strong on empathizing (69\% above the Mean) and weak on systemizing (31\% above the Mean), thus belonged to High-Low group. Systemizing group based on 
"D" score are weak on both of empathizing (17\% above the Mean) and systemizing (31\% above the Mean), thus belonged to Low-Low group. As a consequence, above results further demonstrated that group who scored higher on either empathizing or systemizing also scored higher on resilience.

Table 4 CD-RISC scores for five brain types

\begin{tabular}{|c|c|c|c|}
\hline & \multicolumn{3}{|c|}{ Brain type classification } \\
\hline $\begin{array}{c}\text { CD-RISC } \\
\text { score }\end{array}$ & $\begin{array}{c}\text { based on D } \\
\text { score }\end{array}$ & $\begin{array}{c}\text { based on E } \\
\text { score }\end{array}$ & $\begin{array}{c}\text { based on S } \\
\text { score }\end{array}$ \\
\hline 80.32 & HE & H & L \\
\hline 72.90 & HS & L & H \\
\hline 61.89 & E & H & L \\
\hline 52.20 & S & L & L \\
\hline 43.88 & B & L & L \\
\hline
\end{tabular}

Above results were also consistent with my correlation test results that not only empathizing but also systemizing were significantly positively correlated with individual resilience.

Although the disadvantages of systemizing-oriented people could be the poor social support, helplessness, isolation, however, the advantages for those who are fascinated by analyzing structured things and even indifferent to people-related things, are possibly being immune from external negative impact. As for the empathizing-oriented individuals, permanent and strong social connection and interaction were meant to provide empathizing-oriented people with enjoyable relationship and psychological satisfaction to invigorate them.

\subsection{Gender typical and atypical brain type groups differences in resilience.}

The present study indicated that there was no significant difference in resilience between gender typical and atypical brain type groups. Because the gender typical group comprised of high-systemizing men and high-empathizing women, the gender atypical brain type group comprised of high-systemizing women and high-empathizing men, considering above correlation test results that both of empathizing and systemizing were significantly positively related with resilience, it may due to that both of gender typical and atypical brain type groups were high-resilient enough.

In addition, it may be more scientifically rigorous and potentially valuable to further investigate the raw EQ and SQ scores of typical and atypical based on "D score" by implementing independent sample's T-test of the descriptive statistics. Results indicated that the gender typical brain type group based on "D scores" were strong on empathizing ( $62.5 \%$ above the Mean) and weak on systemizing (42.5\% above the Mean) on average, and therefore belonged to High-Low group. The gender atypical brain type based on "D scores" are strong on both of empathizing (52.6\% above the Mean) and systemizing (52.6\% above the Mean), and therefore belonged to High-High group. Above further analysis results may suggest that although there was no significant difference in resilience between gender typical and atypical brain type groups up to now, there was a trend that the gender atypical brain type groups were strong on both of empathizing and systemizing. Consequently, future studies could investigate whether the atypical group shared a range of strengths in empathizing and systemizing separate and conjunctive dimensions, which enabled them to bounce back from adversities.

\section{CONCLUSION}

The present study mainly focused on resilience of modern Chinese university students. The influential variables and indicators which dominated individual resilient capacity in the concrete situations, could be explored by distinct approaches and tools of biological sex, empathizing and systemizing, gender typical and atypical brain type groups. Although the present study found no significant difference in resilience between men and women, gender typical and atypical brain type group, it innovatively uncovered significant difference in resilience between empathizing-oriented and systemizing-oriented individuals Both empathizing and systemizing were found positively correlated with resilience. Evidence suggests that the gender brain types of empathizing and systemizing serve better as the indicator to predict individual resilience when facing daily life events in comparison with biological sex, gender typical and atypical brain type groups.

As far as empathizing concerned, it was consistent with my hypothesis that empathizing positively related with resilience. For systemizing, it may be explained that individuals of high systemizing are more likely to achieve greater academic achievements compared with low systemizing peers, such as getting good grades, having a great command of programming. It could be inferred that those who exceled in tasks among peers would enjoy more sources and receive better supports, which enabled them to adapt to difficulties and challenges better.

In a broader sense, with the era of science and technology booming and flourishing, the feedback of words such as "nerdy" and "geek" which closely related with systemizing are gradually changing from negative to positive as mobile phones and computers are indispensable and significant for modern people, such as "geek is chic" [34]. People may adore individuals of high systemizing instead of previously looking down upon them. Consequently, participants may hold the view that high-systemizing was superior and more advantageous than low-systemizing, and therefore are more inclined to report higher systemizing.

Furthermore, Zhang (2018) [35] indicated that strengthening teenagers' sex role identity was possible to 
improve their resilience. Future research could include measures of social desirability and sex role identity to examine whether the sex role identity of masculinity and femininity could be regarded as the influential mediating factor among resilience, systemizing and empathizing brain types.

Additionally, the E-S theory stemmed from autism research which the male brain type played the leading role, and may be criticized by the circular reasoning, the present resilience study not only attempted to catch a newly predictor, but it also could strongly test the E-S theory by investigating respective resilience of individuals of empathizing and systemizing, gender typical and atypical brain type groups.

To sum up, as Southwick et al., (2014) [26] indicated, resilience was a multilayer concept which related with socioeconomic status, community environment and numerous variables. The powerful determinants of resilience may vary from person to person from the multidisciplinary perspectives.

\subsection{Limitations}

First, most previous studies limited their sample to adolescents and adults from western countries, this study focused on the transitional period of Chinese undergraduates whose age are 19-23 to bridge the age gap in resilience, and therefore should be critically generalized to other population. Second, as Bonanno \& Mancini (2008) [27] demonstrated, resilience was correlated with a range of variables (e.g. family economic status, educational status, cultural background); nevertheless, present study has been experimented without controlling for above factors owing to limited data. Third, due to the fact that participants completed the self-report questionnaires, the score that they reported maybe biased to their real empathizing, systemizing, and resilient capacity. Participants as undergraduates in ivory tower only received theoretical knowledge were not apt to catch what the CD-RISC referred to difficulties. Additionally, the total number of items of EQ, SQ and CD-RISC was up to 140 , it probably led to participants' impatience to finish the scale, and further impacted the results. Fourth, Although I took the $\mathrm{M} \pm 0.8 \mathrm{SD}, \mathrm{M} \pm 0.6 \mathrm{SD}$ as the cut-off points to apply to the "individual difference in resilience by brain types" and "gender typical and atypical brain type groups difference in resilience" based on "D" scores, after trials and errors of other cut-off points of $\mathrm{M} \pm 0.2 \mathrm{SD}, \mathrm{M} \pm$ $0.6 \mathrm{SD}, \mathrm{M} \pm 0.8 \mathrm{SD}, \mathrm{M} \pm \mathrm{SD}$, it remains a scientifically discussion on where to make the best cut-off points according to the corresponding sample sizes. Under such circumstances, it is important to bear in mind that the generalizability of the present study is limited.

\subsection{Contributions and future direction}

The contribution of present study would be introducing new perspectives of analyzing and constructing individual differences in resilience based on empathizing and systemizing. Resilience as a widely researched topic may could be better analyzed and understood by the gender brain types of empathizing and systemizing, gender typical and atypical brain type groups. Additionally, my study maybe refresh and strengthen the understanding for empathizing and systemizing tendency, and further weaken and mediate the stereotypes that men in higher systemizing and women in higher empathizing, and therefore improve people's tolerance [36].

The application of my research could be that fostering students purely according to their biological sex but blind to more dominating brain sex is prone to be counterproductive. As is shown in above discussions, resilience is interacting and correlating with many variables, taking these factors into consideration is conducive to offer more effective and corresponding psychological counselling varying college students' individual dominating psychological variables. Additionally, the educators should pay great attention to cultivating and honing both of college students' empathetic and systematic capacities. The empathetic capacity enabled human beings as social animals to interact with each other properly, whereas the systematic capacity enabled us to analyse the basic laws in the world. To some extent, empathetic and systematic capacities are equally essential and balancing with each other is of help to promote modern university students' physically and mentally sustainable development in the long run.

\section{ACKNOWLEDGMENT}

Thanks for my teacher and the people who helped me. Without your patient assistance, conscientious efforts, persistent instructions, it was impossible for me to enjoy the process of completing the paper.

\section{REFERENCES}

[1] Wang Jinyang \& Li Chunhua. (2016). Research on the current state of depression of college students.

[2] Cao Wenjun, Guan Zhenjun, Wu Ting, Wang Jinyan, Wang Ruijun, \& Liu Xudong. (2017). Depression symptoms of major students and their correlation with health promotion behavior [J]. Chinese School Health.

[3] Ibrahim, A. K., Kelly, S. J., Adams, C. E., \& Glazebrook, C. (2013). A systematic review of studies of depression prevalence in university students. Journal of Psychiatric Research, 47(3), 391-400. https://doi.org/10.1016/j.jpsychires.2012.11.015 
[15] De la Fuente, J., Cardelle-Elawar, M., Martínez-Vicente, J. M., Zapata, L., \& Peralta, F. J. (2013). Gender as a determining factor in the coping strategies and resilience of university students. Handbook of Academic Performance, 205-217.

Mingiin \& Yang Xinguo. (2019). The Influence of Five Factor Model on Middle School Students'Suicidal Ideation: the Mediating Effect and Regulating Effect of Mental Resilience.

[6] Smith, B. W., Dalen, J., Wiggins, K., Tooley, E., Christopher, P., \& Bernard, J. (2008). The brief resilience scale: Assessing the ability to bounce back. International journal of behavioral medicine, 15(3), 194-200.

[7] Zimmerman, M. A., Stoddard, S. A., Eisman, A. B., Caldwell, C. H., Aiyer, S. M., \& Miller, A. (2013). Adolescent resilience: Promotive factors that inform prevention. Child development perspectives, 7(4), 215-220.

[8] Wang Qinqin. (2013). The Research on the Relation between College Students'Resilience and School Adaption.

[9] Zhao Jing \& Chen Shisheng. (2018). College Students' Stress and Intrinsic Motivation : The Mediating Effects of Resilience.

[10] GUAN Tian-yu et al. (2018). A Research on the Resilience of the Colege Students and Parents Upbringing and Interpersonal Skills.

[11] Zhang Yunhong. (2014). The Resilience and Its Relationship with Psychological Crisis of College Students.

[12] Tugade, M. M., \& Fredrickson, B. L. (2004). Resilient individuals use positive emotions to bounce back from negative emotional experiences. Journal of personality and social psychology, 86(2), 320.

[13] Benetti, C., \& Kambouropoulos, N. (2006). Affect-regulated indirect effects of trait anxiety and trait resilience on self-esteem. Personality and Individual Differences, 41(2), 341-352. https://doi.org/10.1016/j.paid.2006.01.015

[14] Dumont, M., \& Provost, M. A. (1999). Resilience in Adolescents: Protective Role of Social Support, Coping Strategies, Self-Esteem, and Social Activities on Experience of Stress and Depression. Journal of Youth and Adolescence, 28(3), 343-363. https://doi.org/10.1023/A:1021637011732
[16] Sneed, J. R., Johnson, J. G., Cohen, P., Gilligan, C., Chen, H., Crawford, T. N., \& Kasen, S. (2006). Gender differences in the age-changing relationship between instrumentality and family contact in emerging adulthood. Developmental Psychology, 42(5), 787.

[17] Morano, C. (2010). Resilience and coping with trauma: Does gender make a difference? Journal of Human Behavior in the Social Environment, 20(4), 553-568.

[18] Baron-Cohen, S. (2002). The extreme male brain theory of autism. Trends in cognitive sciences, 6(6), 248-254.

[19] Baron-Cohen, S., Auyeung, B., Ashwin, E., Knickmeyer, R., Lombardo, M., \& Chakrabarti, B. (2011). The Extreme Male Brain Theory of Autism: The Role of Fetal Androgens. https://doi.org/10.1093/med/9780195371826.003.0062

[20] Wakabayashi, A., Baron-Cohen, S., Wheelwright, S., Goldenfeld, N., Delaney, J., Fine, D., ... Weil, L. (2006). Development of short forms of the Empathy Quotient (EQ-Short) and the Systemizing Quotient (SQ-Short). Personality and Individual Differences, 41(5), 929-940. https://doi.org/10.1016/j.paid.2006.03.017

[21] Baron-Cohen, S., \& Benenson, J. F. (2003). Books and arts-essential difference: Men, women and the extreme male brain/essential difference: The truth about the male and female brain. Nature, 424(6945), 132-132.

[22] Goldenfeld, N., Baron-Cohen, S., Wheelwright, S., Ashwin, C., \& Chakrabarti, B. (2007). Empathizing and systemizing in males, females and autism: A test of the neural competition theory. https://doi.org/10.1017/CBO9780511543753.019

[23] Svedholm-Häkkinen, A. M., Ojala, S. J., \& Lindeman, M. (2018). Male brain type women and female brain type men: Gender atypical cognitive profiles and their correlates. Personality and Individual Differences, 122, 7-12. https://doi.org/10.1016/j.paid.2017.09.041

[24] Manson, C., \& Winterbottom, M. (2012). Examining the association between empathising, 
systemising, degree subject and gender. Educational Studies, 38(1), 73-88.

[25] Valla, J. M., Ganzel, B. L., Yoder, K. J., Chen, G. M., Lyman, L. T., Sidari, A. P., ... Belmonte, M. K. (2010). More than maths and mindreading: Sex differences in empathizing/systemizing covariance. Autism Research, 3(4), 174-184. https://doi.org/10.1002/aur.143

[26] Southwick, S. M., Bonanno, G. A., Masten, A. S., Panter-Brick, C., \& Yehuda, R. (2014). Resilience definitions, theory, and challenges: Interdisciplinary perspectives. European Journal of Psychotraumatology, 5(1), 25338. https://doi.org/10.3402/ejpt.v5.25338

[27] Bonanno, G. A., \& Mancini, A. D. (2008). The Human Capacity to Thrive in the Face of Potential Trauma. PEDIATRICS, 121(2), 369-375. https://doi.org/10.1542/peds.2007-1648

[28] Svedholm-Häkkinen, A. M., \& Lindeman, M. (2016). Testing the Empathizing-Systemizing theory in the general population: Occupations, vocational interests, grades, hobbies, friendship quality, social intelligence, and sex role identity. Personality and Individual Differences, 90, 365-370.

[29] Wakabayashi, A., Sasaki, J., \& Ogawa, Y. (2011). Sex differences in two fundamental cognitive domains. Journal of Individual Differences.

[30] Fu, C., Leoutsakos, J.-M., \& Underwood, C. (2014). An examination of resilience cross-culturally in child and adolescent survivors of the 2008 China earthquake using the Connor-Davidson Resilience Scale (CD-RISC). Journal of Affective Disorders, 155, 149-153. https://doi.org/10.1016/j.jad.2013.10.041

[31] Wang, L., Shi, Z., Zhang, Y., \& Zhang, Z. (2010). Psychometric properties of the 10-item Connor-Davidson Resilience Scale in Chinese earthquake victims: Chinese version of the 10-item CD-RISC. Psychiatry and Clinical Neurosciences, 64(5), 499-504.

https://doi.org/10.1111/j.1440-1819.2010.02130.x

[32] Iimura, S., \& Taku, K. (2018). Gender differences in relationship between resilience and Big Five personality traits in Japanese adolescents. Psychological reports, 121(5), 920-931.

[33] Focquaert, F., Steven, M. S., Wolford, G. L., Colden, A., \& Gazzaniga, M. S. (2007). Empathizing and systemizing cognitive traits in the sciences and humanities. Personality and Individual Differences,
43(3),

$619-625$.

https://doi.org/10.1016/j.paid.2007.01.004

[34] Tocci, J. (2009). Geek Cultures: Media and Identity in the Digital Age. 460.

[35] Zhang xue. (2018). Emotional Neglect and Resilience-Mediating Role of Sex-Role Identity for Teens. Advances in Psychology, 08(10), 1559-1666. https://doi.org/10.12677/AP.2018.810180

[36] Qin, Y., \& Baker, D. S. (2018). Developing an Implicit Association Test to Explore Implicit and Explicit Stereotypes of Empathy in Scientists among University Students in England. 288. 